\title{
Affiliate marketing. Can online news portals use successfully affiliated marketing in Albania?
}

\author{
Brunilda Beleraj
}

PhD Cand., Ismail Qemali, University of Vlora, Vlora Albania

\begin{abstract}
Affiliate marketing is viewed as one of the online strategies that help marketers' measure success and deal with productivity. Marketers use it as a starting point to create new business or to develop an existing one. Affiliate programs support and develop these new strategies of marketing. Affiliate marketing is performance-based marketing where merchants reward affiliates commission for successful referrals. In Albania, we have chosen some of the most ranked online companies to see how this new techniques could be implemented to benefit both parts. Some of the research questions that have been raised in this paper are; how are the affiliated marketing techniques used in information portals in Albania? Under what conditions those web sites are developed? What payment fees are better to be used? In the evidence of a descriptive research, this paper will make an attempt to answer these questions.
\end{abstract}

Keywords: Online news portals, Affiliate marketing, Potential

\section{Introduction}

Affiliate marketing has become an important strategy of customer acquisition. With the use of Internet, a business can create a network of affiliate organizations that refer customers to its site. Possible affiliations include sellers of products and services, web sites connecting a group of customers with joint interests, or professional referral services. It is expected to become a major source of customer acquisition by many online merchants (Dysart, 2002; Fox, 2000), and industry servers expect (Fox, 2000).

Affiliate marketing occurs where a third-party advertises products or services on behalf of a merchant in return for an agreed commission for a sale or lead. As a result, affiliates are sometimes viewed as an extended sales force for a website (Stokes, 2010).

Affiliate marketing is mainly used for E-Commerce websites; however, it doesn't have to be limited to this. If other parts on site are valuable, it may be worth considering engaging an affiliate. Many merchants pay affiliates a referral fee for every referral that is converted into a customer (pay-per conversion).

For a long time, marketers have not been satisfied by the effectiveness of their advertising campaigns. Most display ads (banner ads) require an advertiser to pay as soon as a website serves an ad to the user, and almost all search ads require an advertiser to pay as soon as a user clicks an add.

Affiliate marketing payment rules are created to protect advertisers against wasted expenses.

For example, when buying display advertising, an advertiser is worried that few users will click its ads: Perhaps the ads are irrelevant to users' interests or are placed in locations where few users notice. Some of these factors are outside the advertiser's control (Zhu and Kenneth, 2011). Standard contracts let advertising networks decide which sites show a given advertiser's add. Under these circumstances, advertisers perceive serious risks that their banner advertising expenditures will be wasted. Similarly, an advertiser buying search ads risks extra expense if uninterested users, competitors, or fraudsters click or purportedly click (Zhu and Kenneth,

2011). 
One interesting characteristic of affiliate marketing is that there are no up-front costs to either the host or the sponsor (Zeff and Aronson 1997). The sponsor, however, faces some hidden costs of entering into an affiliate relationship with too many partners.

The ideal host site for an affiliate sponsor would be one that attracts the same, or similar, customers that is interested. This in turn implies that the host should be the one that retails products and shares similarities with the products sold by the affiliate sponsor. The problem then is identifying the relationships among the different product categories.

This is similar to the category management problem faced by traditional retailers and extensively

explored in the retailing literature (Ludwig, 2012). In this case, the marketers' chief interest is studying demand substitutability (within product categories) and demand complementarily (across product categories) to guide decisions with respect to merchandising, store layout decisions, and so forth (Russell and Kamakura, 1997).

\section{Literature review}

\subsection{Online Advertising and Affiliate Marketing}

The concept "online advertising" has many definitions. (Chaffey,2000) claims that advertising takes place when advertiser pays to place advertising content on another website. Internet advertising is a traffic building campaign - a method to increase the audience of a website.

Online advertising is a form of promotion that uses the Internet and World Wide Web (WWW) to deliver marketing messages to attract customers.

For content providers, online advertising is an important revenue stream. They can sell advertising space to the merchants to promote their products and services (Chaffey, 2000).

Content providers have four options to sell the advertising space: direct selling, site representation firm, ad network and auctions.

Recently another option named affiliate marketing has been used effectively. Affiliate marketing is an agreement between a merchant and content providers to promote merchants' products or services on their websites.

Merchants are called advertisers in online marketing and they pay for the content providers' services only when visitor from their website execute a specified action. Such action can be a purchase of a product for example, filling in a form with personal data, subscribing to a newsletter etc.

\subsection{Who are affiliates?}

Affiliates are specializing in different areas and offering different types of affiliate marketing on their websites. There are some types of them:

Type 1: Niche content and personal interest websites

Affiliates run websites that cater to a certain niche in the online marketplace and can be an ideal way for merchants to target users specifically interested in certain products and drive great quality traffic. Websites that would fall into this category include sites offering free bias, information on certain hobbies or topics, games and bingo websites, and retail and travel-related sites.

Type 2: Loyalty and reward websites

Loyalty and reward websites build a loyal user base by marketing merchants to their users and then share their profits with them. They can share these profits by offering pure cash back to users or awarding them points that can be used to contribute towards discounted online purchases through the website.

Type 3: PPC and search affiliates

Pay per click (PPC) and search affiliates bid on words and phrases in search engines to help drive traffic to a merchant's website by using the sponsored links on portals such as Google, Yahoo, etc. Affiliates are now able to use brand terms and 
improve merchant rankings within the natural portal listings. This is called organic search engine optimization (SEO). Merchants are able to choose whether they wish their products to have affiliates bidding to promote them. If they do, they must then decide whether affiliates may bid on brand terms or just generic terms. Brand term means using the actual merchant name, whereas generic term refers to using a genre or topic to bid on the product.

Type 4: Email marketers

Email affiliates send stand-alone email campaigns to their users. Companies have been set-up specializing in this form of affiliate marketing and have expansive and comprehensive lists which allow merchant's to target specific niches within their target market. Email marketers tend to be paid on a cost per thousand (CPM) bases.

Type 5: Affiliate networks

Affiliate networks are establishing themselves as 'top tier' affiliates exposing merchant offers to their own networks of affiliates while providing account management and assistance where needed. These large scale networks are often capable of providing email marketing, co-registration, PPC and classic affiliate banners, and skyscrapers to run on their affiliate's websites.

Type 6: Co-registration affiliates

Co-registration is a fairly new form of affiliate marketing and allows users to choose offers from third-party merchants whilst registering on a website, but only with the user's full approval. Registration details are passed on to the merchant who then pays the affiliate for the users details.

\subsection{Advantages and Disadvantages of Affiliate Marketing}

Affiliate marketing is beneficial both for merchants and affiliate marketers (Ludwig, 2012).

Merchants can hire various independent websites to advertise their products and services. Advertiser of merchant can only pay the content providers if the ad actually leads to a sale and advertising costs move from fixed to variable costs on ad in affiliate marketing. It can facilitate allocating money to advertising.

Even content providers can enjoy various advantages from affiliate marketing. It offers content providers new chances to generate revenues from their websites offering them the opportunity to cooperate with large number of merchants, which they would not have access otherwise (Russell and Wagner, 1997).

Some disadvantages are observed in affiliate marketing. Accounts of false and misleading types of advertising that lead to unjust claim and also complaints people. The shady and illegal practices involved in this kind of business include false advertising, unlawful use of trade names, logos, or other branding, spamming and hijacking. Merchants sometimes intentionally close down programs without informing the affiliates and paying commissions.

Sometimes affiliates engage in false advertising and misleading the customer in order to get commission. This means that some affiliates sometimes make claims and promises regarding the product and services which are completely wrong or they extremely exaggerate it. When this happens, the merchant usually suffers complaints and they definitely lose potential customer.

As affiliate ads pay out on results, content providers do not have any guarantees that they will make money. They may have to try a number of different affiliates to find those that their visitors respond to. Content providers should have a good idea of the profile of people that visit their site to ensure their target customers appropriately. The time from placing the ad up to getting payment can be several months depending on the affiliate schemes or network content provider register with.

\subsection{Affiliate marketing pricing mode}

The following, are the main types of affiliate marketing models (Affiliatefix, 2014):

CPM or cost-per-thousand impressions, is one of the oldest metrics for affiliate marketing. Merchants will pay publishers a fixed rate for every thousand impressions their advertisement is served. Targeted traffic is regarded better. 
CPC or cost-per-click marketing is one of the moods where publishers charge a fee for an individual click delivered to the merchant's site or program. Costs will vary per click and will be significant to the competition within the sector or niche.

CPL or cost-per-lead is used in sectors where the customers' acquisition isn't always completed in a single online session. It can vary from gathering something as simple as an email address to a large form or action. Leads are priced according to the corresponding criteria.

CPD or cost-per-download is the process of the merchant paying when downloading or installing. Otherwise known as costper-install, the CPD model has seen a significant increase with the rise of mobile advertising and apps.

CPC or cost-per-call, also known as pay-per-call, is the pricing model where by merchant will pay on a call-in basis. Publishers will get customers to qualify a purchase or transaction by calling a specific number.

CPA or cost-per-action is the most popular model for direct response marketers. Merchants are almost guaranteed profit as they only pay per action, which is set out in the initial stages. The payout differs on the level of action that is required, for example, an email submission will pay less than a full form submission.

Tenancy pricing model is where the merchant or advertiser pays a flat, fixed fee per month regardless of the amount of impressions, clicks or leads. Although the results can be hard to measure, and there's no guarantee it will work, the tenancy model can offer large coverage for big companies and brands.

Hybrid pricing model is the combination of several of the above. It's used when a merchant wants to track and focus on the whole purchase or funnel of the offer. Offering different models across one process can really benefit publishers and merchants.

Revenue share is when the merchant agrees to share a commission or portion of the conversion with the publisher. It is often used when a customer may be spending money on a product or program more than several times.

Most affiliate marketing programs, will work on one or several of the above pricing models.

\subsection{Traffic}

Internet traffic is the flow of people and data across the internet. In order to get conversions or views on your affiliate marketing campaigns, it is necessary to know how to gain traffic. The definition of traffic is basically the amount of viewers on your website.

Internet traffic comes in many forms. However, it can often be separated into paid or free. Paid traffic is usually leveraging off someone else and paying for it. Most of the time, paid traffic can be instant, though often you are put through an approval process. For example, if someone were to buy some advertising space on a website, it would be classed as paid traffic. In many instances, a budget or funding is needed in order to get started with paid traffic, as sometimes you're required to pay prior to the traffic coming in. Any online platform or service that demands you pay prior to, or after, for website traffic, falls under the paid traffic category.

For example Google ads, Facebook ads, any real time bidding or self-serve platform will all fall under paid traffic. The cost and pricing model comes down to how targeted and volatile the specific niche of the traffic is. The more popular and targeted it is, the more you will be paying for the traffic, in most cases.

\section{Free Traffic}

The opposite of paid traffic is free traffic. This is traffic that you don't directly pay for to be sent to your site. Using a variety of methods, free traffic can be sent to your website without a payment for it. Free traffic methods can take longer, especially with something like SEO (search engine optimization).

Free traffic comes in many shapes and forms. However, the most popular methods are those of SEO and social marketing. For instance, if someone has a large Facebook Fan Page for his niche and direct users to the site via a status update, that is free traffic you haven't had to pay for. Another example would be if you were able to rank a keyword on the first page of 
Google for your site and you didn't pay for any ranking. The traffic you would be receiving from Google would be free traffic.

Obviously, if you have a budget, paid traffic is a faster way? But, if your budget it limited then free traffic is your choice. Longevity, on the one hand, can be achieved from free traffic. On the other hand, paid traffic is often used for a short burst, making it successful for specific campaigns (Neeman, 2013).

When learning affiliate marketing, it is easy to get lost in multiple traffic sources. The key is to pick one or two and master them. Most new affiliate marketers will start on free traffic since funds are low and it is a great way to learn the basic. Then they decide to move into paid traffic when they have a larger budget, giving them the option to test different sources.

\subsection{Important Choices for affiliate marketing}

According to (Affiliatefix.com, 2017) an affiliate should take into consideration:

\section{Gender breakdown:}

This split is pretty even and in line with the general population which is; $51 \%$ male and $49 \%$ female.

Age breakdown:

Affiliate marketing is certainly something anyone can do. The distribution of age is interesting and encouraging to anyone interested in generating additional income from affiliate marketing efforts.

Income for ages are; Age 22-25: 2.5\%, Age 26-30: 22\%, Age 31-40: 19\%, Age 61+: 9\%.

Work location:

Many affiliates enjoy the flexibility of working at home and balancing maximum efficiency and comfort; while others still commute to the office or split their time between both. Affiliate that work from home: $59 \%$, Commute to office: $18 \%$ and Both: $23 \%$.

Traffic generation:

Every affiliate has its secrets to generate traffic to the websites; this is what makes them unique. While these methods don't vary too much; thus, providing insight into what traffic channels are working, where the volumes at and what's profitable for others. Affiliates love free traffic, which is obvious with SEO, Social, Blogging and Word of Mouth, all top the charts.

Traffic generation from:

Search Engine Optimization: 79\%,Social Networks: 60\%, Blogging: 59\%, Word of Mouth: 37\%, Email Marketing: 28\%, Pay Per Click: 27\%, Video or Images: 21\%, Display Advertising: 19\%, Offline Marketing: 16\%, Comment Marketing: 12\%, Guest Posting: $11 \%$, Other: $5 \%$.

Product promotion:

While retail and consumer products and services are certainly the lion's share of the offers out there, you can't forget about business products. What's interesting is how few affiliates solely dedicate their efforts towards driving business-to-business products.

Product promotion goes:

B2C: $69 \%$, B2B: $1.3 \%$, Both: $29.7 \%$.

Contact method:

Affiliates almost unanimously prefer to be contacted via email. While some networks and relationships may support methods of contact outside email, it's very uncommon. Contacts Methods are; Email: 91\%, IM: 4\%, Phone: 8\%, All of the above: $7 \%$, Other: $1 \%$. 
Selecting merchants:

When affiliates were asked what their top 3 factors (Affiliatefix.com, 2017) are when selecting what merchant to promote, commission remains on top, more so than the relevancy of the product or service. What is really interesting is that affiliate network/tracking platform was the 3rd more important factor. When merchants are looking to launch their affiliate program, keeping that in mind can do wonders for affiliate recruitment. Commission $62 \%$, product or service relevancy: $54.4 \%$, affiliate network or tracking platform: $36.7 \%$, brand awareness: $34.2 \%$, merchant reputation: $31 \%$, cookie duration: $24.1 \%$, affiliate program reputation: $24.1 \%$, payment terms and methods: $17.1 \%$, terms and conditions: $16.5 \%$, earnings per click: $15.2 \%$, other: $9.5 \%$, ads and landing pages: $7 \%$.

\section{Finding programs:}

Affiliates are constantly seeking out new affiliate programs to join, especially as their traffic increases or diversify. Although, affiliates are most likely to reach out and request joining an affiliate program, most likely through a network, advertisers should know that them reaching out to the affiliate is still a common practice. Affiliates also use search engines to find affiliate programs. As an advertiser, having a Pay per Click strategy in place to include affiliate program related keywords can help increase your affiliate base. Affiliate info on merchant's website: $51 \%$, affiliate Manager reaches out directly: $42 \%$, search engine searches: $39 \%$, affiliate or CPA network: $38 \%$, check competitor's websites: $26 \%$, word of mouth: $20 \%$, affiliate manager website: $15 \%$, conferences: $9 \%$, other: $8 \%$, print publications: $4 \%$.

\section{Program promotion:}

Most affiliates are specialists in their niche, which means they generally only promote closely related products and advertisers (Affiliatefix.com ,2017). Almost half of affiliates this last year were promoting 10 or fewer programs. Over $75 \%$ promote fewer than 50 affiliate programs, 1 - 10: 47\%, 11 - 20: 16\%, 21 - 50: 14\%, 51 - 100: 6\%, $101-200: 3 \%, 201$ - 300: $1 \%, 300+: 12 \%$.

Network affiliation:

To join a network, merchants are usually charged to launch or to set it up. For affiliates though, it is almost always free to join(Affiliatefix.com, 2017). This enables them to belong to several networks, in some cases, every network. A good network will have high quality merchants, reliable tracking, affiliate-friendly tools and sophisticated reporting, among other things.

Ranking of network affiliation are; ShareASale: $83.7 \%$, Commission Junction: $77.8 \%$, LinkShare: $58.2 \%$, LinkConnector: 43.1\%, ClickBank: 41.2\%, PepperJam: 35.3\%, AvantLink: 21.6\%, Impact Radius: 17\%, Affiliate Window: 15.7\%, Digital River: $13.7 \%$.

\section{Methodology}

For affiliates, keeping up to date with merchants, other affiliates and the industry is probably the key to growth (Stokes, 2010). Joining forums and keeping tabs on industry leaders will help do just that. So the information from forums and websites is relevant. We used forums, web sites, academic journals and books to gain secondary data for the research purpose.

Primary data. As traffic is one of the evidence of successful affiliate marketing, we first found evidence of the most ranked sites in Albania. Statistics were used from alexia.com part of amazon.com, as one of the most successful affiliates site (Ranking.com, 2017). Ranking (the number of sites linking in Alexa reports is the number of websites in Alexa's crawl of the web that link to a given website) is a rough estimate of this site's popularity.

The rank is calculated using a combination of average daily visitors to this site and its page views over the past 3 months. The site with the highest combination of visitors and page views is ranked \#1. (Aleksa.com). We chose 30 of the first websites. From them we selected only Albanian online journals or news portals (not Kosovo's site).

We used observation technique as an instrument of collecting data. (Marshall and Rossman 1989), define observation as "the systematic description of events, behaviors, and artifacts in the social setting chosen for study" in qualitative research. 
For a Period of Two weeks we observed the pages of the websites selected. We found the companies ads on their web sites. We grouped them in two categories: affiliate and on line ads. Then for each of them we used the consumer ghost technique to gather information from their websites as price per ads (do they use affiliate programs etc.).

\section{Research Question}

1. How are affiliated marketing techniques used in information portals in Albania?

2. Under what condition the new portal webs are developed?

3. What payment technique is better to use?

4. Should there be used an affiliated program or can these portals be affiliated on their own?

\section{Findings}

The emerging world of blogs must be understood within the larger context of a changing global news arena where the public naturally seeks perspectives beyond one specific locality and nation (Croad, 2003). The migration of news and information to an online platform has disrupted old patterns of reading and changing the relationship between audiences and news providers.

As traffic is one of the evidence of successful affiliate marketing, we first found evidence of the most ranked sites in Albania. We used alexia.com part of amazon.com as one of the most successful affiliate sites. Ranking (the number of sites linking in Alexa reports is the number of websites in Alexa's crawl of the web that link to a given website) is a rough estimate of this site's popularity. In the thirty first sites ranked, we found five Albanian Information Portals or online newspapers. The other sites were web portal from Kosovo (5), international websites as face book, youtube etc( 5), and the other were entertainment pages. The results and its respective ranking is as follow for the News Portal:

\begin{tabular}{ll} 
Web site/publisher & Ranking \\
& \\
Balkanweb.com & 8 \\
Shekullionline.com & 24 \\
\hline Shqiptarja.com & 25 \\
\hline Gazetatema.al & 27 \\
Panorama.com.al & 29 \\
\hline
\end{tabular}

Table nr.1 The ranking of websites

The new e-paper technology has provided the newspaper companies with the possibility of publishing a portable digital enewspaper with the same readability as in print media. The e-newspaper is converging print and online with the best from two worlds, i.e. the overview and familiar design of the printed edition and the interactivity and continuous updates of the web. An online newspaper is created by the convergence of the newspaper and the Internet. As Chyi and Sylvie (2001) describe "technologically, the Internet enables online newspapers to seek a world-wide market. Most online newspapers are owned by their print counterparts, also serve as online editions' primary content providers". According to (Boczkowski, 2004) the emergence of online newspapers has occurred "partly as a reaction to major socioeconomic and technological trends, such as changing competitive scenario and developments in computers and telecommunications - trends that, in turn, online newspapers have influenced".

Table 1 shows a high ranking of these portals. Thus, the first condition for successful affiliate marketing from these portals is evident. These portals may serve as affiliates, bringing benefits for merchant and portals to. Ranking is an important evidence, but is not enough. We need to see other element of these portals.

\begin{tabular}{|l|l|l|}
\hline Web site/publisher & Nr. of adds & Nr. of affiliate adds \\
\hline Balkanweb.com & 12 & 1 \\
\hline
\end{tabular}




\begin{tabular}{|l|l|l|}
\hline Shqiptarja.com & 11 & 0 \\
\hline Panorama.com.al & 11 & 2 \\
\hline Shekullionline.com & 12 & 2 \\
\hline Gazetatema.al & 10 & 0 \\
\hline
\end{tabular}

Table $\mathrm{nr}$ 2. Ads for the websites

As we mentioned above ads and affiliate marketing are close to each other. They differ in the payment fee. From the observation process we noted that these portal use affiliate marketing in a restricted way. The merchant are international and they belong to the trade of clothes and to the industry of download programs. Than we made a web analyses of the merchant that actually use this portals. Some of them can be affiliate one. For an average of 12.35 daily pages view, affiliate ads of Balkanweb.com, can be adopted to the content of each page. While "Shekulli on line" can use the highest daily time on site and a high daily pages view. All sites have a high number of links that bring visitors to their sites. That is another advantage that this web can use to attract sellers to their sites. "Shqiptrja.com" has an advantage in the number of links.

Table nr. 3 shows the industry that actually use these portals to advertise their activities.

\begin{tabular}{|l|l|l|l|l|}
\hline Web site/publisher & Percentage of albanian visitors & $\begin{array}{l}\text { Daily time on site } \\
(\mathrm{min})\end{array}$ & $\begin{array}{l}\text { Daily pages } \\
\text { view }\end{array}$ & Links \\
\hline Balkanweb.com & $60 \%$ & 5.65 & 12.35 & 1425 \\
\hline Shekullionline.com & $47.60 \%$ & 21.52 & 8 & 1033 \\
\hline Shqiptarja.com & $75.50 \%$ & 9.44 & 4.98 & 271 \\
\hline Gazetatema.al & $55 \%$ & 9.57 & 4.83 & 1268 \\
\hline Panorama.com.al & $62,9 \%$ & 8.01 & 3.78 & 1175 \\
\hline
\end{tabular}

Table nr.3 Important statistics

\begin{tabular}{|l|l|l|l|}
\hline Web site/publisher & 1 Keywords $\%$ & 2 Keywords in $\%$ & 3 Keywords in $\%$ \\
\hline Balkanweb.com & $0 \%$ & $100 \%$ & $0 \%$ \\
\hline Shekullionline.com & $25 \%$ & $75 \%$ & $0 \%$ \\
\hline Shqiptarja.com & $0 \%$ & $100 \%$ & $0 \%$ \\
\hline Gazetatema.al & $0 \%$ & $100 \%$ & $0 \%$ \\
\hline Panorama.com.al & $50 \%$ & $50 \%$ & $0 \%$ \\
\hline
\end{tabular}

Table nr.4 Keywords

How to maximize the keyword activity?

Most customers have a feel for where they want to go online, and typically perform multiple searches, but research by (Onestat, 2017) also shows the importance of covering generic long tail keywords:

- 2 word queries currently account for $30 \%$ of Searchqueries

- 3 words: $27 \%$

- 4 words: $17.1 \%$

- 5 words: $8.25 \%$

- 6 words: $3.7 \%$

The use of Keywords is not optimal. Most webs use two keywords. This will affect the web search engine.

Using at list two words will increase the possibility of finding the right site. This is crucial for Panormal.com.al, Shekullioniline.com and Telegrafi.com. 
Keywords will increase the possibility of finding the right site.

\section{Average prices of ads.}

Using the concept "Customer ghost", entire representative portal webs above were contacted, as e representative of a construction company in Vlora. We asked them for the prices of their ads. The average prices listed above. We use the average price for two reasons:

Little difference between prices is noted in different online portals.

2. For ethical issues. As we used the costumer ghosts, we decided not to mention prices of ads for this portals;
1.0PTION 1 (Width: 980px and Height: 100px) $\rightarrow$
120,000 lek
2.0PTION 2 (Width: 140px and Height: 1500px) $\rightarrow$
110,000 lek
3 .OPTION 3 Width: 140px and Height: 1500pX $\rightarrow$
110,000 lek

4.0PTION 4 (Width: 90px and Height: 80px, only image) $\rightarrow 30,000$ lek

5.0PTION 5 (Width: 222px and Height: 80px, only image) 45,000 lek

6.0PTION 6 (Width: 90px and Height: 80px, only image) $\rightarrow$ 30,000 lek

7.0PTION 7 (Width: 300px and Height: 250px) $\rightarrow \quad$ 100,000 lek

8.0PTION 8 (Width: 300px and Height: 250px) $\rightarrow \quad 90,000$ lek

9.0PTION 9 (Width: 300px and Height: 250px) $\rightarrow \quad 80,000$ lek

10.0PTION 10 (Width: 300px and Height: 250px) $\rightarrow \quad 70,000$ lek

11.0PTION 11(Width: 480px and Height: 90px) $\rightarrow \quad 55,000$ lek

12.0PTION 12 (Width: 480px and Height: 90px) $\rightarrow \quad 50,000$ lek

13.0PTION 13-16 (Width: 135px and Height: 300px) $\rightarrow \quad 60,000$ lek

17.0PTION 17 (Width: 970px and Height: 50px) $\rightarrow \quad 90,000$ lek

These were the average fees for the month.

Since March 22, 2011, a feature has been added into the Adsense Reporting system, where we can see the ad performance based on countries. This is the raking that compile with around 10 million ad impressions from 10 sites of different nature. Hopefully it helps in deciding which countries to target. A smart publisher should target those on top of the list.

01 - $\$ 0.48$ - Australia

02 - \$0.44 - Netherlands Antilles

03 - \$0.43 - Denmark

04 - \$0.41 - Switzerland

05 - $\$ 0.36$ - South Africa

71 - $\$ 0.04$ - Albania

In this, Albanian web affiliates have a little payment. Part of it goes to cover the cost of the process.

\begin{tabular}{|l|l|l|l|l|l|l|l|l|l|}
\hline $\begin{array}{l}\text { Web } \\
\text { sites/publisher }\end{array}$ & $\begin{array}{l}\text { Telecommunicatio } \\
\mathrm{n} \text { In. }\end{array}$ & $\begin{array}{l}\text { Bank } \\
\mathrm{s} \text { In. }\end{array}$ & $\begin{array}{l}\text { Game } \\
\mathrm{s} \text { In. }\end{array}$ & $\begin{array}{l}\text { Constructio } \\
\mathrm{n} \text { In. }\end{array}$ & $\begin{array}{l}\text { Healt } \\
\mathrm{h} \\
\text { care } \\
\text { In. }\end{array}$ & $\begin{array}{l}\text { Foods } \\
\text { and } \\
\text { beverag } \\
\mathrm{e} \text { In }\end{array}$ & $\begin{array}{l}\text { Travel/ } \\
\text { Accommodatio } \\
\mathrm{n} \text { In. }\end{array}$ & $\begin{array}{l}\text { Othe } \\
\mathrm{r}\end{array}$ & $\begin{array}{l}\text { T0 } \\
\mathrm{T}\end{array}$ \\
\hline Balkan web.com & 3 & 3 & 0 & 1 & 3 & 0 & 1 & 1 & 12 \\
\hline
\end{tabular}




\begin{tabular}{|l|l|l|l|l|l|l|l|l|l|}
\hline $\begin{array}{l}\text { Shekulli } \\
\text { online.com }\end{array}$ & 2 & 2 & 0 & 1 & 2 & 2 & 1 & 1 & 11 \\
\hline Shqiptarja.com & 2 & 1 & 0 & 2 & 2 & 1 & 1 & 2 & 11 \\
\hline Gazetatema.al & 2 & 2 & 0 & 1 & 2 & 1 & 1 & 2 & 12 \\
\hline $\begin{array}{l}\text { Panorama.com. } \\
\text { al }\end{array}$ & 2 & 2 & 1 & 1 & 1 & 1 & 1 & 1 & 10 \\
\hline Total & 11 & 10 & 1 & 6 & 10 & 5 & 5 & 7 & \\
\hline
\end{tabular}

Table.5 Web portals and current industries adds

According to the table above, all the industries have enough space to attract firms toward affiliate marketing. So, the company that does not use ads in the web can be invited to use affiliate marketing.

\section{Conclusions}

Albanians are among the most passionate internet users in Europe, having achieved the second highest growth in this area of the world from 2006 to 2010. Albanians have one of the highest mobile phone usage rates in Europe. The mobile phone penetration in the end of 2011 breached the 185\% level. Albania is also the first country in the world having achieved 100\% electronic public procurement services (Akep, 2017)

The space that the actual affiliate ads use is relatively small. The visitors stay enough in site to see more than 10 ads, which is the average of ads. Specially the banking industry, the food, the health care are represented from a little number of firms that use ads in these sites. If the marketers of these portals offer a marketing platform, when they can pay for performance, there are good possibilities for this merchant to use affiliated marketing (Marshall, et al., 1995).

The ideal host site for an affiliate sponsor would be one that attracts the same, or similar, customers in which it is interested. This in turn implies that the host should be one that retails products that share some commonality with the products sold by the affiliate sponsor. The problem then is identifying the relationships among the different product categories

These portals can attract small and medium business using these strategies. They have little financial power and such a strategy will help them to use effective marketing techniques.

Seasonal activity can be attracted from these sites and be effective too. For the inbound travel industry it can be a good opportunity. Nearly $25 \%$ percents off actual viewers belong to Albanians who live in countries like Italy, Greece, USA, and Germany. They use these portals to be informed about their country. Often they came to spend holidays in their country and need accommodation. So small and medium firms off accommodation or travel can use affiliate marketing.

Another important issue is that visitors on this web sites go from on portal to the other(Alexa.com, 2015). So nearly of 40 $\%$ of the visitors go to visit another portal immediately after they have visited one. They want to compare information with other issues. The differences between target audiences in these portals make the merchant choice much easier.

For all Ads (except for 4 of them) the payment is a fix one. Affiliate marketing requires a payment on performance.

According to the industries for the telecommunication, banking, food and music industry, the affiliate, can pay the system per view or pay per click. This industries rarely use on line buying. Hotels and traveling industries can use the payment pay per action or pay per lead.

According to the research result we can conclude as follow;

1. Affiliate marketing as a new technique is used rarely from the news portals in Albania. Most of them use ads technique.

2. The condition to develop affiliate marketing in news portals in Albania is favorable as shown in the tables above.

3. The best mode to pay for affiliate marketing it would be a variable one, because the fix one is already used for ads. Further studies will make it clear which is the best technique.

4. The news portals can use an affiliate program as it is a new technique for them. 


\section{Recommendations}

Affiliate marketing is a new concept in Albania. With the development of internet/online advertisement is increasing day by day. In affiliate marketing, content providers provide online marketing and advertising facilities for advertisers where they (advertisers) pay for their advertisements. Rapid development of online marketing indicates better possibilities and opportunities of affiliate marketing in online advertisement. Content providers should offer a variety of options available for online advertising on the website for their users. By providing quality service, affiliate marketing can become a greater source of revenue. In near future, it will gain more popularity and users will be able to buy their products sitting at home by placing orders just watching the advertisement. For selling advertising space of the website, affiliate marketing is very much significant to the content providers. To accelerate and conduct the affiliate marketing effectively, several recommendations are made:

-Content providers should recommend high quality product or service.

- Content providers should affiliate to link straight to individual products, rather than just the home page (otherwise visitors might not go for the next step). "Pay-per-sale" and "Pay-per-lead" are good payment models for content providers.

-Content providers should give the prospective customer content surrounding the niche with the products relate to.

-Content providers should build a process that allows them to choose products that sell easily. In addition it allows not choosing products subjectively.

\section{Limitation}

1. The first limitation comes from professional knowledge of the news portals about affiliate marketing. Most of them do not have knowledge about it.

2. The second limitation comes from the mode of gathering primary date. The ghost client technique may be a genuine one, but it is not a complete one.

\section{References}

[1] Boczkowski, P. J. (2004). Digitizing the News: innovation in online newspapers. MIT Press, New Baskerville.

[2] Chaffey, D. (2003). Internet Marketing Strategy, Implementation and Practice, 2 nd . New York: Financial Times, New York.

[3] Chyi, H. I. \& Sylvie, G. (2001). The Medium is Global, the Content is Not: The Role of Geography in Online Newspaper Markets. Journal of Media Economics.

[4] Croad, E. (2003) 'US Public Turns to Europe for News', 21 February, URL (consulted January 2017): www.journalism.co.uk/news/story576.html

[5] Dysart, J. (2002). "Click-Through Customers," Bank Marketing, 34(3), 36-41.

[6] Edelman, B. The design of online advertising markets. In NirVulkan, Alvin Roth, and

[7] Fox, L. (2000), "Affiliate Marketing Makes Headway."

[8] Hoffman, D. , Novak, T.(2000). How to Acquire Customers on the Web?

[9] https://productforums.google.com/forum/\#!topic/adsense/EifekCvzz-A (Accessed 3 June 2017).

[10] https://www.itu.int//TU-D/treg/publications/BBD_MDG_Albania_Final.pdf (Accessed 3 June 2017).

[11] Ludwig, T. (2012). The Beneficial Benefits of Affiliate Marketing.

[12] Marshall, C. \& Rossman, Gretchen B. (1995). Designing qualitative research 2002. Choosing the Right Mix of On-Line Affiliates: How Do You Select the Best?

[13] Neeman, Z. (2012). "The Handbook of Market Design". Oxford University Press, 2013.

[14] Russell, G. and Wagner K.(1997). Modeling Multiple Category Brand Preference with Household Basket Data", Journal of Retailing.

[15] Stokes, R. (2013)"E marketing. The essential guide to marketing in a digital World" 5 th edition.

[16] Wilson, R. F. (2005). Repon on Affiliate IManagement Software 2005: The Essential Merchant's Buying Guide.

[17] www. blog.affiliatetip.com ( Accessed 1 June 2017).

[18] www.akep.al Accessed 1 June 2017).

[19] www.aleksa.com (Accessed 1 June 2017).

[20] www.amazon.com (Accessed 1 June 2017). 
[21] www.balkanweb.com.al (Accessed 1 June 2017).

[22] www.gazetatema.net (Accessed 1 June 2017).

[23] www.iab.net (Accessed 1 June 2017).

[24] www.insatat.com.al (Accessed 1 June 2017).

[25] www.nbkarticles.com/business/businessideas/1725-the-beneficial-benefits-of- affiliate-marketing.(Accessed 2 June 2017)

[26] www.onestat.com. Accessed 2 June 2017)

[27] www.panorama.com.al (Accessed 2 June 2017).

[28] www.shekulli.com.al (Accessed 2 June 2017).

[29] www.wilsonweb.com/ebooks/afniisoft.htm. (Accessed 1 June 2017).

[30] Zeff, R. \& Aronson, B. (1997). Advertising on The Internet, New York: John Wiley \& Sons.

[31] Zhu, Yi and Kenneth C. Wilbur (2011), "Hybrid Advertising Auctions," Marketing Science, 30(2): 249-273 